\title{
Trunk muscle activation during golf swing: Baseline and threshold
}

\author{
Luís Silva $^{\mathrm{a}, *}$, Sérgio Marta ${ }^{\mathrm{a}}$, João Vaz ${ }^{\mathrm{a}}$, Orlando Fernandes ${ }^{\mathrm{b}}$, Maria António Castro ${ }^{\mathrm{c}}$, \\ Pedro Pezarat-Correia ${ }^{a}$ \\ ${ }^{a}$ Faculty of Human Kinetics, Technical University of Lisbon, Portugal \\ ${ }^{\mathrm{b}}$ University of Évora, Portugal \\ ${ }^{\mathrm{c}}$ Coimbra College of Health Technology, Polytechnic Institute of Coimbra, Portugal
}

\section{A R T I C L E I N F O}

\section{Article history:}

Received 5 October 2012

Received in revised form 24 April 2013

Accepted 28 May 2013

\section{Keywords: \\ EMG \\ Threshold \\ Trunk \\ Onset \\ Golf swing}

\begin{abstract}
A B S T R A C T
There is a lack of studies regarding EMG temporal analysis during dynamic and complex motor tasks, such as golf swing. The aim of this study is to analyze the EMG onset during the golf swing, by comparing two different threshold methods. Method A threshold was determined using the baseline activity recorded between two maximum voluntary contraction (MVC). Method B threshold was calculated using the mean EMG activity for $1000 \mathrm{~ms}$ before the $500 \mathrm{~ms}$ prior to the start of the Backswing. Two different clubs were also studied. Three-way repeated measures ANOVA was used to compare methods, muscles and clubs. Two-way mixed Intraclass Correlation Coefficient (ICC) with absolute agreement was used to determine the methods reliability.

Club type usage showed no influence in onset detection. Rectus abdominis (RA) showed the higher agreement between methods. Erector spinae (ES), on the other hand, showed a very low agreement, that might be related to postural activity before the swing. External oblique (EO) is the first being activated, at $1295 \mathrm{~ms}$ prior impact. There is a similar activation time between right and left muscles sides, although the right EO showed better agreement between methods than left side. Therefore, the algorithms usage is task- and muscle-dependent.
\end{abstract}

(c) 2013 Elsevier Ltd. All rights reserved.

\section{Introduction}

Several approaches have been proposed for EMG onset detection; however there is no standardized method and its application is mainly done in motor skills with isometric contraction (Farina and Merletti, 2000), as they present better reproducibility (Lee et al., 2011). A complex motor skill such as a golf swing combines both power and precision. The purpose of the golfer is to place a ball inside a small hole with the least hits possible (Hume et al., 2005). Although it is not considered an intensive and exhausting sport, skeletal-muscle stress and demand are associated with high injury incidence (Cabri et al., 2009).

The study of onset muscle activity can provide information regarding the temporal organization and coordination of a set of muscles at use during a task (De Luca, 1997). In explosive and precise motor tasks, as throwing, the trunk muscles sequence plays an important role in the organization of the proximo-distal sequence in order to transfer energy (Hirashima et al., 2002). This

\footnotetext{
* Corresponding author. Address: Praceta João de Deus 5, 2 D, 2855-221 Corroios, Portugal.

E-mail address: luisbsilva@hotmail.com (L. Silva).
}

mechanism leads to an increase of speed in distal segments. The movement of different body segments will depend on the motor programming of the central nervous system, which translates into a specific sequence, intensity and muscle time activation. In subjects with low back pain, the reaction time (activation to movement initiation) of abdominal muscles tends to increase as upper limb task complexity increases, due to postural organization (Hodges, 2001).

Most studies on trunk muscle EMG activity during a golf swing have focused on intensity parameters (Pink et al., 1993; Watkins et al., 1996). Only two studies have analyzed the EMG activation onset (Horton et al., 2001; Cole and Grimshaw, 2008). Both have used a threshold detection algorithm, and compared trunk muscles between symptomatic and asymptomatic golfers' lower back pain. Horton et al. (2001) used seven standard deviations (SDs) above baseline, with a $200 \mathrm{~ms}$ window (i.e. time interval considered for a group of samples). Although they did not find differences for the amplitude of abdominal activity between the two groups, asymptomatic subjects activated the left external oblique (EO) significantly earlier than the symptomatic, in respect to the start of the backswing. Cole and Grimshaw (2008) have set the onset at $1 \mathrm{SD}$ above baseline, with a $50 \mathrm{~ms}$ moving window. Their results did not present significant differences between the two groups 
for EO, but the erector spinae (ES) was activated significantly sooner for golfers with low back pain. The difficulty in comparing studies is related to the different algorithms criteria, which compromises the reproducibility of the results (Morey-Klapsing et al., 2004; Jöllenbeck, 2000). This is particularly evident for threshold algorithms (Staude et al., 2001).

Onset detection can be divided into two categories: visual inspection (VI) and detection algorithms (Vaisman et al., 2010; Hug, 2011). Visual inspection requires a time-consuming work and the precision of the results depends on the researcher's expertise; therefore being a subjective process (Jöllenbeck, 2000) and its use being rather paradigmatic. However, the lack of a goldstandard measurement used to validate the algorithms, leads to visual inspection being used to assess the precision of threshold algorithms. Algorithms Detection can be classified into threshold algorithms (Van Boxtel et al., 1993; Hodges and Bui, 1996; Jöllenbeck, 2000; Allison, 2003) and as statistically optimized algorithms (Micera et al., 1998; Staude et al., 2001), as maximum likelihood.

The usual definition of onset refers to the initial activity register of the motor units' action potentials (Solnik et al., 2010). The different phases that make up complex motor skills would require different approaches for the meaning of EMG signal. McGill et al. (2010) characterizing a double-peak intensity phenomenon in motor skills such as kicking in martial arts. This phenomenon could be associated with the muscular actions during the different phases of those tasks. For golf swinging several phases can be discriminated, such as the preparation (backswing), execution (downswing) and result (follow-through). Some authors have opted to include descriptive and qualitative movement analysis, due to activity characteristics and particular muscle actions (Hirashima et al., 2002; McGill et al., 2010).

The precision with which a certain algorithm detects the onset is influenced by the background activity level, signal-to-noise ratio activity (Hodges and Bui, 1996; Staude et al., 2001), and onset rate of signal amplitude (Allison, 2003). Hug (2011) states that threshold algorithms vary in 1, 2, and 3 SD or between $15 \%$ and $25 \%$ of the activity's maximum peak. Other threshold algorithm approaches have considered onset to be the moment in which signal voltage/ intensity surpasses the confidence interval upper limit in a fixed number of samples (Van Boxtel et al., 1993). Hodges and Bui (1996) which have compared onset detection algorithms with different options of low pass filters $10,50,500 \mathrm{~Hz}$ combined with different sampling windows $10,25,50 \mathrm{~ms}$ and standard deviations 1 , 2 , 3 SD for different background activity levels. The most adequate combinations for cutoff frequency, sample window and SD were are $50 \mathrm{~Hz} / 25 \mathrm{~ms} / 3 \mathrm{SD}$ and $50 \mathrm{~Hz} / 50 \mathrm{~ms} / 1 \mathrm{SD}$. This clearly demonstrated that excessive smoothing leads to loss of information, and that insufficient smoothing is associated with an onset detection delay.

Parameters knowledge on what constitutes the detection of algorithms is crucial on EMG temporal analysis. However, this analysis should not be restricted to isometric contractions. Temporal activity should take into account the dynamic motor skills phases, identifying key moments of motor coordination.

Golfers often wonder whether the swing is always the same when using different clubs. Swing phase time seems to be similar, but the club speed could be different (Egret et al, 2003), although there is a lack of knowledge on the activation timing in using different clubs.

The aim of this study is to analyze the temporal activity during the golf swing given the preparation phase (backswing) and execution phase (downswing) by comparing the use of two different baselines, activity threshold methods and visual inspection. Moreover, we intend to investigate whether or not the usage of different clubs leads to changes in the onset detection.

\section{Method}

\subsection{Participants and task}

Eight male right-handed amateur golfers $(52.0 \pm 7.4$ years old; handicap of $15.7 \pm 3.2)$ were instructed to perform five precision swings with pitching $(<100 \mathrm{~m})$ and five long range swings with iron $4(>150 \mathrm{~m})$ in an alternate sequence $(n=80)$. Before any experimental procedure, subjects were allowed to perform some repetitions, in order to enable a better adaptation to the task and to warm up. The swings were carried out on top of an artificial grass golf carpet with high absorption features. Subjects did not have any limitations for playing golf. All the procedures were explained and a consent form was signed. This study was approved by the Ethics Committee of the Faculty of Human Kinetics (Technical University of Lisbon).

\subsection{Video recording and analysis}

Three high speed Basler A602fc cameras (Basler Vision Technologies, Ahrensburg, Germany) at $100 \mathrm{~Hz}$ were placed in position as to determine swing phases. A fourth Casio Ex-FH20 camera (Casio, Tokyo, Japan) at $1000 \mathrm{~Hz}$ was placed in front of the ball, in order to determine the instant of impact. Two reflective tapes (Horton et al., 2001) were placed on the club to divide the swing in three phases (Bechler et al., 1995; Pink et al., 1993; Watkins et al., 1996). (1) Backswing - from the beginning until the top of the swing; (2) Downswing - from the top until impact; and (3) Follow-Through - from impact until the end of the swing. SIMI 3D Motion system (SIMI Reality Motion System GmbH, Unterschleissheim, Germany) was used for EMG-synchronized 3D kinematic analysis.

\subsection{EMG procedures}

EMG data was collected with active surface electrodes $(\mathrm{Al} / \mathrm{AgCl}$, disk shape $10 \mathrm{~mm}$ of diameter) and bioPLUX ${ }^{\circledR}$ research 2010 telemetric equipment (Plux, Lisbon, Portugal). EMG data was collected with a $1000 \mathrm{~Hz}$ sampling frequency, amplified with a bandpass between 10 and $500 \mathrm{~Hz}$, common-mode rejection ratio (CMRR) of $110 \mathrm{~dB}$ and input impedance greater than $100 \mathrm{M} \Omega$. After stored, data was digitally filtered $(10-490 \mathrm{~Hz})$ and, full-wave rectified. Smoothing with a low pass filter $(12 \mathrm{~Hz}$, Butterworth 4 th order digital filter) was applied and submitted to visual inspection comparison. EMG data processing was performed with MATLAB ${ }^{\circledR}$ V.R2010a software (Mathworks Inc., Natick Massachusetts, USA). Skin was properly prepared by means of hair removal, abrasion and alcohol cleaning. The electrodes were placed with a $20 \mathrm{~mm}$ center-to-center distance and applied in parallel to the muscle fibers: rectus abdominis (RA), $3 \mathrm{~cm}$ laterally from the umbilicus; external oblique (EO), $15 \mathrm{~cm}$ laterally from the umbilicus; erector spinae (ES), $3 \mathrm{~cm}$ laterally from the L3 spinous process (Horton et al., 2001). Muscle contraction was performed in order to visualize the muscle belly. The ground electrode was placed on the manubrium.

Three to four second-long maximum voluntary contractions (MVCs) were collected to determine baseline activity between two maximum voluntary contractions (MVCs): RA - in supine position, the participant performed trunk flexion at $30^{\circ}$, keeping the knees at $90^{\circ}$ and the hip at $70^{\circ}$, with a researcher applying resistance on the shoulders, while another researcher bilaterally stabilized the lower limbs; EO - in lateral position, with hands on the chest and flexed legs (stabilized), the participant produced a lateral trunk flexion against the resistance presented by the researcher; ES - in prone position, with lower limbs stretched and pelvis fixated, the participant performed trunk extension against the bilateral shoulder resistance presented by the researcher (Konrad, 2005; 
McGill, 1991). The participants were verbally encouraged during these tasks to improve their performance.

\subsection{Onset detection}

Two methods for onset detection were used, the difference being on the threshold determination. With method A, the mean for threshold was determined with the baseline activity registered between two MVC (Fig. 1 A). Determination with method B involved the mean EMG activity for $1000 \mathrm{~ms}$ before the $500 \mathrm{~ms}$ prior to the start of the Backswing (Fig. $1 \mathrm{~B}$ ). The threshold value was derived using 3 SD above the baseline mean amplitude. Two additional criteria 1. and 2. were applied after threshold calculation for both methods (A and B): 1 . the search for onset starts $150 \mathrm{~ms}$ before Backswing; 2. the search for a second onset starts $150 \mathrm{~ms}$ before Downswing. Then a 50 -sample window moved until a positive derivative was obtained, in addition to having met the established threshold. These restrictions were used to ensure that the method selects an onset related to a peak activity instead of slightly signal oscillations. The reference for onset calculation was the impact.

EMG onset was also detected through visual inspection performed by two experienced researchers.

\subsection{Statistical analysis}

Data were statistically processed with IBM SPSS Statistics 19.0 (IBM Corporation, New York, USA). Descriptive statistics were presented with average \pm standard deviation and coefficient of variation. Normality test of the data was performed with the Shapiro-Wilk test. Three-way repeated measures ANOVA was used to compare methods, muscles and clubs. Two-way mixed Intraclass Correlation Coefficient (ICC) with absolute agreement was used to determine the methods reliability. Multiple comparisons were done with Bonferroni test, and sphericity was assessed with Mauchly's test. When there was no sphericity, the degrees of freedom were corrected with Greenhouse-Geisser test. The significance level was set at $5 \%$.

\section{Results}

Table 1 shows the descriptive for onset for method A, method B and VI for the restriction $150 \mathrm{~ms}$ before the backswing (A1, B1 and VI1) and for restriction $150 \mathrm{~ms}$ before the downswing (A2, B2, VI2). Data are present for onset results (ms) and percentage of onset detection related to the EMG maximum activity (\%Pmax)

\section{A}

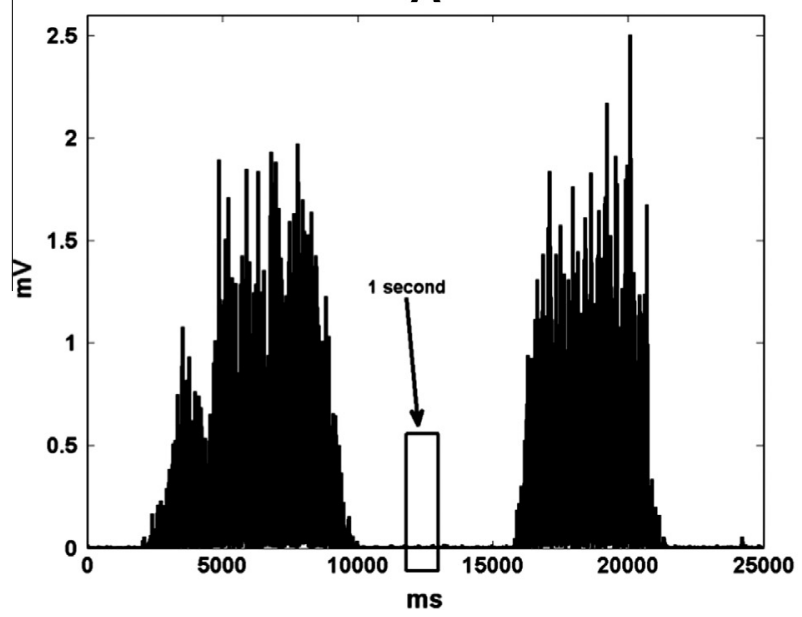

across muscles side and club. In Fig. 2 it can be seen that the restriction 1 corresponds to the onset search starting before backswing (called onset burst), and the restriction 2 the search starts before downswing (called onset peak) due to a phase change in motor task. Three-way ANOVA showed no significant differences between clubs on the detection of the onset detection with the restriction before the backswing (right side muscles $(\mathrm{R})-F_{(1,7)}=$ $2.552, p=0.154, \eta_{p}^{2}=0.267, \pi=0.282$; left side muscles $(\mathrm{L})-F_{(1,11)}=$ $\left.1.910, p=0.194, \eta_{p}^{2}=0.148, \pi=0.244\right)$. For the onset detection with the restriction before the downswing no significant differences were found $(\alpha=0.05 / 8)$ either for the club and both muscles sides $\left(\mathrm{R}-F_{(1,35)}=5.035, p=0.031, \eta_{p}^{2}=0.126, \pi=0.588 ; \mathrm{L}-F_{(1,30)}=\right.$ 4.843, $\left.p=0.036, \eta_{p}^{2}=0.139, \pi=0.568\right)$. There were no significant interactions of the club in onset detection with restriction 1 and 2 in relation to muscles $\left(\mathrm{R}-F_{(1.104,7.727)}=3.247, p=0.109, \eta_{p}^{2}=0.317\right.$, $\left.\pi=0.523 ; \quad \mathrm{L}: \quad F_{(2,22)}=1.724, \quad p=0.202, \quad \eta_{p}^{2}=0.136, \quad \pi=0.322\right)$ $\left(\mathrm{R}-F_{(1.408,49.266)}=4.980, p=0.009, \eta_{p}^{2}=0.125, \pi=0.686 ; \mathrm{L}: F_{(2,60)}=\right.$ $\left.1.803, p=0.174, \eta_{p}^{2}=0.057, \pi=0.363\right)$ neither to the methods $\left(\mathrm{R}-F_{(2,14)}=1.976, p=0.175, \eta_{p}^{2}=0.220, \pi=0.340 ; \mathrm{L}: F_{(2,22)}=0.441\right.$, $\left.p \leqslant 0.649, \eta_{p}^{2}=0.039, \pi=0.113\right)\left(\mathrm{R}-F_{(1.490,52.152)}=3.280, p=0.059\right.$, $\eta_{p}^{2}=0.086, \pi=0.519 ; \quad \mathrm{L}: F_{(2,60)}=0.012, p \leqslant 0.988, \quad \eta_{p}^{2}=0.057$, $\pi=0.363$ ), respectively.

Significant differences were found in onset detection for the three muscles with both restrictions, 1 . $\left(\mathrm{R}-F_{(2,14)}=5.985\right.$, $p \leqslant 0.001, \quad \eta_{p}^{2}=0.461, \quad \pi=0.798 ; \quad \mathrm{L}: \quad F_{(2,22)}=47.482, \quad p \leqslant 0.001$, $\left.\eta_{p}^{2}=0.812, \quad \pi=1.0\right)$ and $2 . \quad\left(\mathrm{R}-F_{(2,70)}=151.941, \quad p \leqslant 0.001\right.$, $\eta_{p}^{2}=0.813, \pi=1.0 ; \quad \mathrm{L}: F_{(1.568,60)}=82.583, \quad p \leqslant 0.001, \quad \eta_{p}^{2}=0.734$, $\pi=1.0)$. The interaction between muscles and methods were also significant for both, restriction $1\left(\mathrm{R}-F_{(4,28)}=13.819, p \leqslant 0.001\right.$, $\eta_{p}^{2}=0.664, \pi=1.0 ; \mathrm{L}: F_{(1.842,20.258)}=9.395, p \leqslant 0.001, \eta_{p}^{2}=0.461$, $\pi=0.999)$, and restriction $2\left(\mathrm{R}-F_{(2.537,88.799)}=68.524, p \leqslant 0.001\right.$, $\eta_{p}^{2}=0.662, \pi=1.0 ; \mathrm{L}: F_{(2.648,79.431)}=71.085, p \leqslant 0.001, \eta_{p}^{2}=0.703$, $\pi=1.0$ ), showing that onset detection is influenced by the method and depend of the studied muscle. Multiple comparisons showed a similarity between method B and VI for the general data of right side for onset detection with restriction $1(p=1.0)$.

Fig. 3 shows the errors bars for onset detections in the RA, EO and ES with method A, method B and visual inspection.

The results for ICC, coefficient of variation and Inter-Item Correlation Matrix are presented in Table 2.

\section{Discussion}

This study analyzed the temporal activity during the golf swing, given the phases of preparation and execution, with the traditional

Fig. 1. (A) Baseline MVC method A; (B) Baseline trial method B; BS: Backswing.

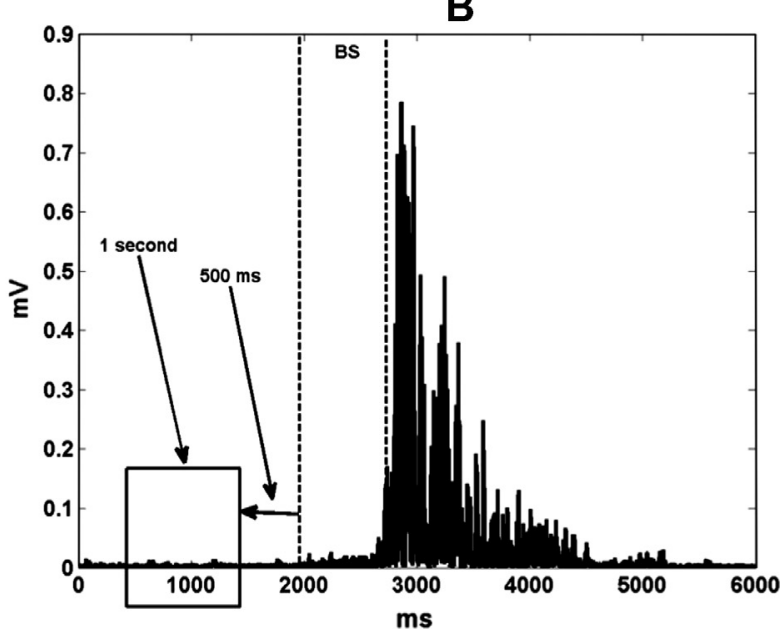


Table 1

Descriptive mean and standard deviation onset type and method.

\begin{tabular}{|c|c|c|c|c|c|c|c|}
\hline \multicolumn{3}{|l|}{ Method/onset Type } & \multicolumn{2}{|l|}{ A1 } & \multicolumn{2}{|l|}{ B1 } & \multirow{2}{*}{$\begin{array}{l}\text { VI1 } \\
\text { Onset (ms) }\end{array}$} \\
\hline Muscle & Side & Club & Onset (ms) & EMG peak \% & $\begin{array}{l}\text { Onset (ms) } \\
\text { Mean [Std. deviation] }\end{array}$ & EMG peak \% & \\
\hline \multirow[t]{4}{*}{ RA } & Right & 4-iron & $-1320.24[276.44]$ & $3.96[3.59]$ & $-1092.56[189.91]$ & $4.58[3.41]$ & $-1039.00[87.12]$ \\
\hline & & Pitch & $-1332.44[230.03]$ & $4.40[4.07]$ & $-1129.59[190.71]$ & $4.94[4.24]$ & $-1031.62[103.68]$ \\
\hline & Left & 4-iron & $-1062.78[274.94]$ & 10.09 [7.57] & $-1003.19[256.78]$ & 10.69 [8.32] & $-914.81[138.83]$ \\
\hline & & Pitch & $-1020.80[271.39]$ & $11.49[9.60]$ & $-883.73[196.81]$ & $12.39[9.62]$ & $-894.83[108.35]$ \\
\hline \multirow[t]{4}{*}{ EO } & Right & 4-iron & $-1359.05[270.83]$ & $5.98[3.74]$ & -1402.38 [259.07] & $5.09[3.35]$ & $-1347.92[240.48]$ \\
\hline & & Pitch & $-1289.76[310.11]$ & $6.37[4.71]$ & $-1335.63[273.05]$ & $5.56[3.87]$ & $-1302.32[256.60]$ \\
\hline & Left & 4-iron & $-1193.76[158.92]$ & $11.25[5.22]$ & $-1290.74[140.32]$ & $6.73[3.60]$ & $-1275.50[134.05]$ \\
\hline & & Pitch & $-1191.50[184.48]$ & $12.04[5.28]$ & $-1263.89[147.23]$ & $7.05[3.68]$ & $-1250.67[111.47]$ \\
\hline \multirow[t]{4}{*}{ ES } & Right & 4-iron & $-1328.29[210.93]$ & $22.58[9.89]$ & $-1010.59[178.66]$ & $31.48[16.31]$ & $-1273.00[157.97]$ \\
\hline & & Pitch & $-1325.19[148.08]$ & $23.04[8.26]$ & $-1056.06[138.11]$ & $35.91[12.36]$ & $-1244.25[138.35]$ \\
\hline & Left & 4-iron & $-1345.35[158.75]$ & $20.32[9.84]$ & $-1090.17[157.96]$ & $31.92[16.13]$ & $-1247.04[125.00]$ \\
\hline & & Pitch & $-1357.10[126.60]$ & 23.10 [12.47] & $-1060.05[187.60]$ & $31.85[15.54]$ & $-1260.00[111.78]$ \\
\hline Method/onset type & & & A2 & & B2 & & VI2 \\
\hline \multirow[t]{4}{*}{$\mathbf{R A}$} & Right & 4-iron & $-442.24[27.00]$ & $8.11[6.04]$ & $-442.24[27.00]$ & $8.11[6.04]$ & $-442.53[44.31]$ \\
\hline & & Pitch & $-434.62[35.46]$ & $7.74[6.53]$ & $-433.97[35.84]$ & $7.77[6.58]$ & $-441.71[39.80]$ \\
\hline & Left & 4-iron & $-426.30[44.87]$ & $18.84[12.10]$ & $-425.46[44.22]$ & $18.94[12.22]$ & -433.51 [56.89] \\
\hline & & Pitch & $-407.53[55.23]$ & $17.97[11.47]$ & $-406.87[54.96]$ & $17.97[11.47]$ & $-419.93[68.82]$ \\
\hline \multirow[t]{4}{*}{ EO } & Right & 4-iron & $-351.44[55.82]$ & $25.27[16.06]$ & $-352.28[56.54]$ & $25.23[16.09]$ & $-339.46[71.45]$ \\
\hline & & Pitch & $-373.55[54.46]$ & 27.19 [21.24] & $-377.29[56.25]$ & 27.05 [21.31] & $-367.74[54.98]$ \\
\hline & Left & 4-iron & -364.58 [71.20] & $40.74[23.25]$ & $-364.58[71.20]$ & $40.74[23.25]$ & $-341.26[90.09]$ \\
\hline & & Pitch & $-364.39[64.72]$ & $41.23[26.39]$ & $-365.33[63.71]$ & $41.16[26.45]$ & $-342.47[73.26]$ \\
\hline \multirow[t]{4}{*}{ ES } & Right & 4-iron & $-374.18[72.26]$ & $2.59[2.89]$ & $-237.71[28.14]$ & $19.78[14.19]$ & -298.65 [42.29] \\
\hline & & Pitch & $-372.25[78.01]$ & $5.45[4.44]$ & $-240.94[51.02]$ & $24.42[12.79]$ & -303.13 [55.19] \\
\hline & Left & 4-iron & $-328.00[67.84]$ & $4.82[3.49]$ & -208.39 [31.39] & $20.90[14.90]$ & $-302.04[65.97]$ \\
\hline & & Pitch & $-341.05[70.01]$ & $4.28[2.34]$ & $-205.10[40.13]$ & $19.95[12.11]$ & $-296.80[58.80]$ \\
\hline
\end{tabular}

RA - rectus abdominis; EO - external oblique; ES - erector spinae.

definition for onset, but also knowing important timing moments against different muscle actions that are associated with these swing phases. As the algorithms' parameters influence the results, we compare two different threshold baseline-related algorithms and visual inspection. Additionally, it was also verified if the club usage influences the performance method in onset detection and timing parameters of the trunk muscles.

This problem arose from a sequence of influences derived from many factors. The first factor refers to the difficulty in comparing different studies, due to a low reproducibility method (Allison, 2003; Morey-Klapsing et al., 2004; Staude et al., 2001), when there is some diversity among algorithms (Hug, 2011). Another factor that was considered refers to the tendency of preferably testing algorithms in maximum voluntary contractions or in monoarticulate actions (e.g. Jöllenbeck, 2000; Wong and Ng, 2005; Soylu and Arpinar-Avsar, 2010), instead of complex dynamic actions. Due to the phases that make up complex actions, the EMG is associated with qualitative changes from one phase to the following phases, which suggests different muscles assuming different roles throughout motor skills (Cordo et al. 2003; McGill et al., 2010). In a golf swing, which is a complex dynamic action, so far there have been few studies on temporal parameters (Horton et al., 2001; Cole and Grimshaw, 2008).

\subsection{Onset detection methods and maximum peak percentage}

When considering the task phases, backswing and downswing, they can be addressed as two temporal onsets: onset burst and onset peak (Fig. 2). The initial activity of the motor unit action potentials (Solnik et al., 2010) will be the onset burst, whereas the on/off muscle activity occurring before the peak in the execution phase will be considered as the onset peak in this study. The relevance of this phenomenon is to study motor skills and the performance accuracy in detection algorithm.

Discriminating the baseline during the relaxation between two consecutive MVCs and the swing trial background activity, a good agreement was found for the onset peak among the three methods for RA on both sides the left $(\mathrm{R}-\mathrm{ICC}=0.958$; $\mathrm{L}-0.957$ ) and the right EO (ICC $=0.906)$, however in the last one the agreement with VI was lower than for the RA. For the RA, consistency given by the variation coefficient was also similar between methods (Table 2 ). By observing the detection of onset burst for the RA, results ( $R$ ICC $=0.563$; $\mathrm{L}-0.0 .479$ ) which are different and conflicting than the onset peak. First, the onset burst does not occur in all subjects as can be observed in Fig. 1 for the right RA. Second, when the activity of the onset burst is considered, it is detected after the backswing. The phenomenon that was repeated in all subjects is the onset peak, but could be simultaneous with the onset burst in several cases because there was no activity besides the baseline, and the detection made for the restriction 1 was not validated by the VI. The pattern for the right RA starting its activation $438 \mathrm{~ms}$ before impact ( $8 \%$ Pmax) regardless of the threshold method used for determination (method A or B), and $442 \mathrm{~ms}$ with VI. The results are somewhat similar in the left RA, the method A and B showed 418 (8\% Pmax) ms, and VI $427 \mathrm{~ms}$.

EO onset peak, besides the good correspondence among methods $(\mathrm{R}-\mathrm{ICC}=0.906 ; \mathrm{L}-0.0 .837$ ), the inter correlation with VI varied from 0.517 to 0.681 and was detected at $26 \%$ Pmax for the right EO and $41 \%$ Pmax for the left EO, both at \pm 364 ms before the downswing, much for method $\mathrm{A}$ and $\mathrm{B}$. Onset burst detected in the EO had a high agreement $(\mathrm{R}-\mathrm{ICC}=0.906$; $\mathrm{L}-0.0 .837)$ therefore being similar to the VI, as was the case for the onset peak found in the RA. Another similarity refers to the percentage of peak that occurs at very low values between $5 \%$ Pmax in the right EO with method $\mathrm{B}$ and $12 \%$ Pmax in the left EO with method A. The EO is the first muscle which is being activate, independently of the side, about $1260 \mathrm{~ms}$ before impact with method A and $1324 \mathrm{~ms}$ with method B.

For the ES it becomes difficult to distinguish where the burst onset is, because this muscle is already activated due to the forward leaning of the trunk during the address and the moments preceding the swing. This is coincident with the high background activity, then method B presents a high threshold. The onset burst was detected at 22\%Pmax with method A and $33 \%$ with method B 

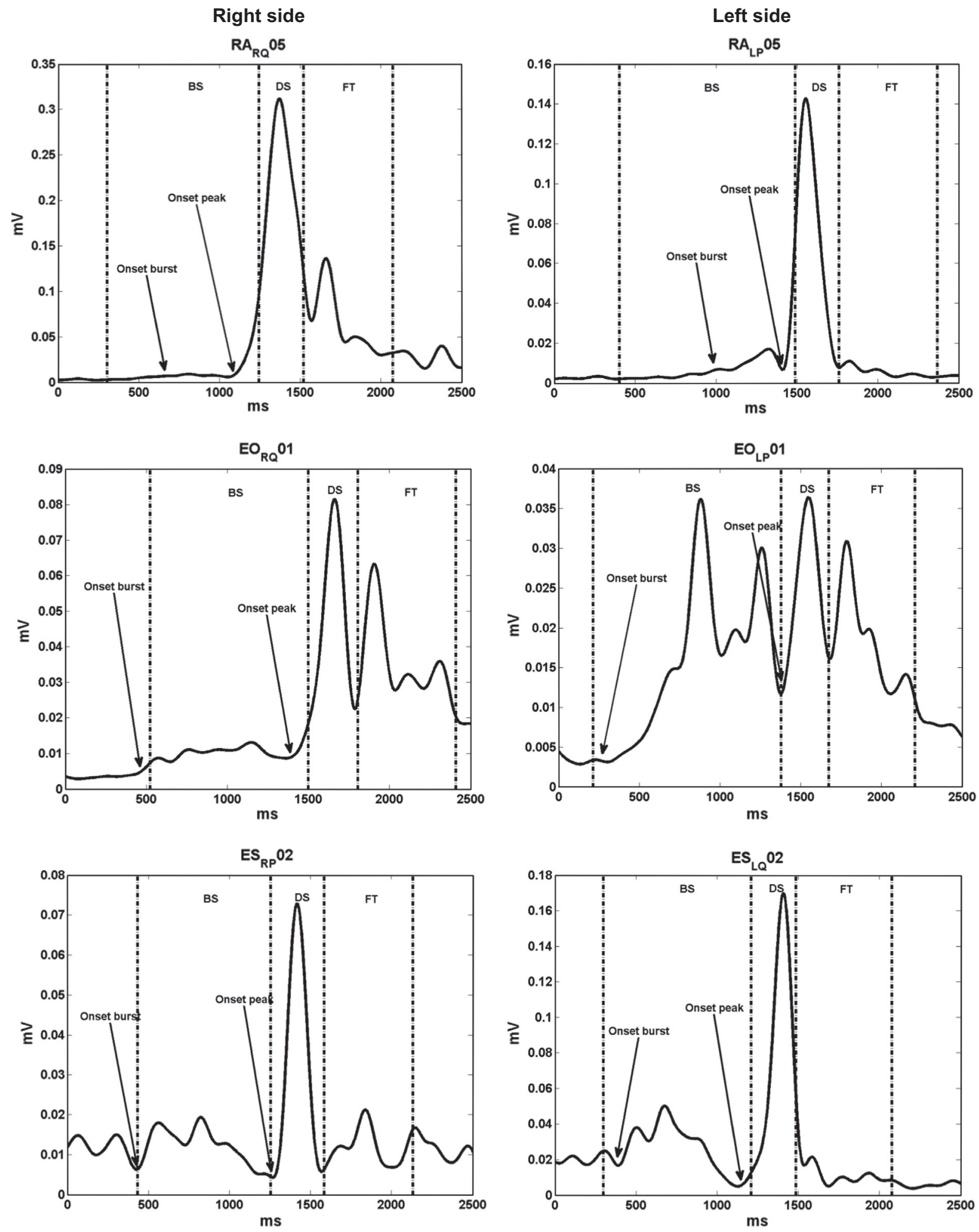

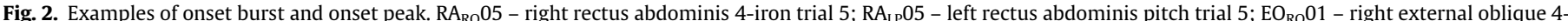
iron trial 1; $\mathrm{EO}_{\mathrm{LP}} 01$ - left external oblique pitch trial 1; $\mathrm{ES}_{\mathrm{RP}} 02$ - right erector spinae pitch trial 2; $\mathrm{ES}_{\mathrm{LQ}} 02$ - left erector spinae 4-iron trial 2.

and the agreement with VI was low $(\mathrm{R}-\mathrm{ICC}=0.365$; $\mathrm{L}-\mathrm{ICC}=$ 0.214 ), but method A showed a better correlation. A higher signal-to-noise ratio leads to a better resemblance between the methods, and the reverse situation otherwise (Staude et al., 2001). Both automatic methods detected the onset peak in ES, which is a timing pattern in all the subjects characterized by intensely turning off/turn on the muscular activation. Nevertheless, the value agreement amongst the three methods was lower ( $\mathrm{R}-\mathrm{ICC}=0.374$; L $-\mathrm{ICC}=0.277$ ), method A being nearest to VI. A high EMG activity baseline is common in postural tasks, leading to an onset detection delay in respect to visual inspection (Hodges and Bui, 1996). The use of different methods for ES demonstrated that method B delays onset detection, in comparison to method A. Method A detected onset peak at a mean of $351 \mathrm{~ms}$ before 

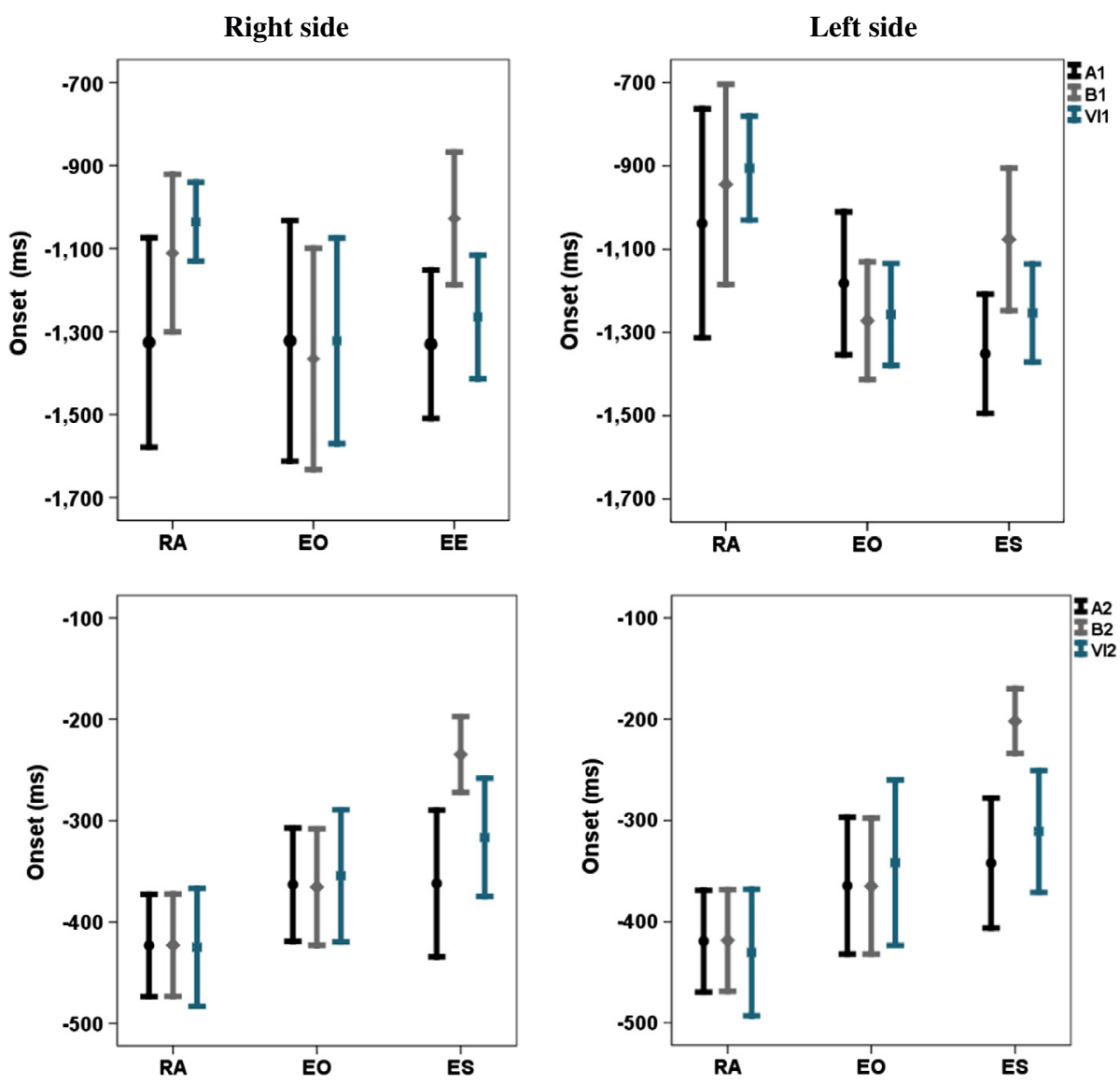

Fig. 3. Error bars methods A (A1, A2), method B (B1, B2) and visual inspection (IV1, IV2). RA - rectus abdominis; EO - external oblique; ES - erector spinae.

impact (4.4\%Pmax) and method B at $220 \mathrm{~ms}$ (21\%Pmax), while the VI showed $347 \mathrm{~ms}$. The concordance between threshold methods depended on the onset signal amplitude rate. A small rate of signal amplitude implies major temporal changes when different thresholds are used (Allison, 2003).

It is clear in this study that the cut percentage is different from muscle to muscle, regardless of the methods. This leads to adopting differentiation settings for the onset, which depends on the features of muscle signal under study. Hodges and Bui (1996) had already observed the same, which is related to the signal-to-noise ratio, and makes it difficult to precisely pinpoint onset detection (Solnik et al., 2008, 2010). The use of MVC rest activity no longer interferes with this ratio.

Onset detection translated into maximum peak percentage is below the values presented by Hug (2011) for all the muscles that were studied, with the exception of the RA and ES, with method A. These results confirm that percentage threshold methods should use relatively low maximum peak amplitude percentage values, as stated by Jöllenbeck (2000). Nonetheless, this author studied monoarticular limb motor skills. In the present study, the results diverge between muscles due to different behaviors regarding mechanic demand.

\subsection{EMG peak, mechanic demand and club}

EMG represents the muscles' electric activity, but that activity can be associated with other functions which are not directly related to the movement itself (Vaisman et al., 2010), such as postural and/or adjustment. The study of different peaks can be useful as a good guidance in the motor behavior, but it is not advisable to compare absolute latency time with other methods (Wong and $\mathrm{Ng}, 2005$ ).
For RA, we found the existence of a double peak in some participants, although there is consistency regarding maximum peak or the phenomenon being studied is very noticeable. In the the RA, maximum peak occurred at $170 \pm 26 \mathrm{~ms}$ before impact on the right side and at $130 \pm 81 \mathrm{~ms}$ on the left side. The ES was the muscle that showed the maximum activity nearest to impact, $126 \pm 36 \mathrm{~ms}$ on the right side and $85 \pm 31 \mathrm{~ms}$ before impact on the left side. For EO, maximum peak detection presents a higher variability. Firstly, due to the existence of three activity peaks. Another cause is the intra and inter subject regarding the moment of maximum activity, which could happen sometimes in backswing and others in downswing. According to Vaisman et al. (2010) it seems there is a tendency for a higher variability on trunk muscles when comparing them to limb muscles.

Multiple peaks can be associated with auxiliary actions to the agonist activity and with the action that is divergent in the different phases. General muscle activity pattern becomes complex for time patterns, with a qualitative change from one phase to the next, which suggests different function performance (Cordo et al., 2003). For EO, we found an almost simultaneous activation for onset burst in both sides, as if it were a co-contraction process. Theoretically, we would expect an earlier activation for these muscles, i.e. for EO on the left side, due to the fact that the trunk rotation movement was initiated by the right side. Hirashima et al. (2002) analyzed trunk, shoulder and upper limb muscle action for a ball throw. They confirmed that EO contralateral to the arm which performs the throw is activated first, regarding EO ipsilateral.

What happens in the transition from one phase to the other can be an important factor to be studied. Whereas the preparation phase will be subject to adjustment during the task, the movements in ballistic contractions are pre-programmed. When the motor skill that is being studied encompasses preparation and 
Table 2

Statistical correlation and agreement between methods.

\begin{tabular}{|c|c|c|c|c|c|c|c|}
\hline \multirow[t]{2}{*}{ Muscle } & \multirow[t]{2}{*}{ Methods } & \multirow[t]{2}{*}{ Side } & \multicolumn{2}{|c|}{ Onset (ms) } & \multirow{2}{*}{\multicolumn{2}{|c|}{ Inter-item correlation matrix }} & \\
\hline & & & $|C V|$ & ICC [IC95\%] & & & \\
\hline \multirow[t]{6}{*}{ RA } & A1 & $\mathrm{R}$ & 0.19 & $0.563[0.128,0.768]$ & & A1 & B1 \\
\hline & B1 & & 0.17 & & B1 & 0.63 & \\
\hline & VI1 & & 0.09 & & VI1 & 0.597 & 0.471 \\
\hline & & $\mathrm{L}$ & 0.26 & $0.479[0.239,0.658]$ & & & \\
\hline & & & 0.25 & & & 0.247 & \\
\hline & & & 0.14 & & & 0.293 & 0.385 \\
\hline \multirow[t]{6}{*}{ EO } & $\mathrm{A} 1$ & $\mathrm{R}$ & 0.22 & $0.963[0.945,0.976]$ & & & \\
\hline & B1 & & 0.19 & & & 0.909 & \\
\hline & VI1 & & 0.19 & & & 0.908 & 0.913 \\
\hline & & $\mathrm{L}$ & 0.14 & $0.897[0.759,0.947]$ & & & \\
\hline & & & 0.11 & & & 0.826 & \\
\hline & & & 0.1 & & & 0.837 & 0.884 \\
\hline \multirow[t]{6}{*}{ ES } & A1 & $\mathrm{R}$ & 0.14 & $0.365[-0.037,0.645]$ & & & \\
\hline & B1 & & 0.15 & & & 0.151 & \\
\hline & VI1 & & 0.12 & & & 0.766 & 0.003 \\
\hline & & $\mathrm{L}$ & 0.11 & $0.214[-0.089,0.480]$ & & & \\
\hline & & & 0.16 & & & 0.025 & \\
\hline & & & 0.09 & & & 0.399 & 0.133 \\
\hline \multirow[t]{6}{*}{ RA } & A2 & $\mathrm{R}$ & 0.07 & $0.958[0.939,0.972]$ & & A2 & B2 \\
\hline & $\mathrm{B} 2$ & & 0.07 & & B2 & 0.999 & \\
\hline & VI2 & & 0.09 & & VI2 & 0.842 & 0.841 \\
\hline & & $\mathrm{L}$ & 0.12 & $0.935[0.903,0.957]$ & & & \\
\hline & & & 0.12 & & & 0.995 & \\
\hline & & & 0.15 & & & 0.795 & 0.794 \\
\hline \multirow[t]{6}{*}{ EO } & A2 & $\mathrm{R}$ & 0.19 & $0.906[0.863,0.937]$ & & & \\
\hline & B2 & & 0.16 & & & 0.981 & \\
\hline & VI2 & & 0.18 & & & 0.681 & 0.683 \\
\hline & & $\mathrm{L}$ & 0.17 & $0.837[0.757,0.893]$ & & & \\
\hline & & & 0.18 & & & 0.999 & \\
\hline & & & 0.24 & & & 0.517 & 0.518 \\
\hline \multirow[t]{6}{*}{ ES } & $\mathrm{A} 2$ & $\mathrm{R}$ & 0.2 & $0.374[-0.029,0.629]$ & & & \\
\hline & B2 & & 0.17 & & & 0.271 & \\
\hline & VI2 & & 0.16 & & & 0.424 & 0.547 \\
\hline & & $\mathrm{L}$ & 0.2 & $0.277[-0.060,0.537]$ & & & \\
\hline & & & 0.17 & & & 0.121 & \\
\hline & & & 0.21 & & & 0.484 & 0.367 \\
\hline
\end{tabular}

$\mathrm{RA}$ - rectus abdominis; EO - external oblique; ES - erector spinae; $\mathrm{R}$ - right; $\mathrm{L}$ - left.

execution phases, the contraction relaxing contraction relationship could affect EMG behavior, due to the stretch-shortening cycle properties (McGill et al., 2010). For a golf swing, the transition from backswing to downswing is related to energy storage and transfer, in order to favor segment acceleration, followed by deceleration before impact (Cheetham et al., 2008). The double peak phenomenon is associated to different actions in those phases (McGill et al., 2010). The first peak can be associated with the action of stabilizing the trunk before movement starts, whereas the second is related to the dynamic action with its maximum peak occurring next to impact. The results indicate that a threshold algorithm can actually take the phenomenon which is being studied into consideration. Although the threshold is still a critical parameter, it is possible to find literature that suggests an adjustment to the algorithmic criteria of the data under study (Leader et al., 1998).

In the present study, the club does not interfere with different onset detections, although the effect size and power in ANOVA tends to be moderate. Egret et al. (2003) neither found significant differences for the duration of the golf swing performed with three different clubs (driver, 5-iron and pitch), nor for the partial time of golf swing phases. However, there were significant differences for club speed. This leads us to recommend that future studies approach temporal parameters together with kinematic analysis of motor chains.

\section{Conclusion}

The results of this study clearly show the baseline parameter influence in onset detection, during dynamic and complex motor activities. It is also verified that detection performance is dependent on the muscle which is being studied. RA presents a better correlation and concordance between methods, which means, baseline choice did not interfere with onset detection. For EO, onset detection it was similar with both methods, although detection occurred at different levels of maximum activity amplitude. Due to the postural task, ES had a high background activity, delaying onset detection for method B due a high threshold. Although ES was activated before the beginning of the movement, an instant activation which follows a pattern throughout trials was found. This pattern corresponds to the proximity of maximum activity to impact. In all the muscles, the right side showed a better agreement than the left side. Trunk muscles tend to increase their activity near impact. Different thresholds can correspond to similar onset detection, in case the specific muscle activity is translated into a high onset rate of amplitude.

The use of different clubs does not influence temporal parameters of trunk muscles during a golf swing.

\section{Conflict of interest}

None declared.

\section{Acknowledgments}

The project "Neuromuscular activity in the golf swing with implications for the practice and in the prevention of overuse injuries" was supported by the Portuguese Foundation for Science and Technology fund (PTDC/DES/105176/2008) 


\section{References}

Allison GT. Trunk muscle onset detection technique for EMG signals with ECG artefact. J Electromyogr Kinesiol 2003;13(3):209-16.

Bechler JR, Jobe FW, Pink M, Perry J, Ruwe PA. Electromyographic analysis of the hip and knee during the golf swing. Clin J Sport Med 1995 Jul;5(3):162-6.

Cabri J, Sousa JP, Kots M, Barreiros J. Injuries in golf: a systematic review. EJSS 2009;9(6):353-66.

Cheetham PJ, Rose GA, Hinrichs RN, Neal RJ, Mottram RE, Hurrion PD, et al. Comparison of kinematic sequence parameters between amateur and professional golfers. In: Lutz R, Crews D, editors. Science and Golf V. Proceedings of the World scientific congress of Golf. Arizona: Ironwood Lithographers; 2008. p. 30-6.

Cole MH, Grimshaw PN. Trunk muscle onset and cessation in golfers with and without low back pain. J Biomech 2008;41(13):2829-33.

Cordo PJ, Gurfinkel VS, Smith TC, Hodges PW, Verschueren SM, Brumagne S. The situp: complex kinematics and muscle activity in voluntary axial movement. J Electromyogr Kinesiol 2003;13(3):239-52.

De Luca CJ. The use of surface electromyography in biomechanics. J Appl Biomech 1997; 13:135-63.

Egret CI, Vincent O, Weber J, Dujardin FH, Chollet D. Analysis of 3D kinematics concerning three different clubs in golf swing. Int $\mathrm{J}$ Sports Med. 2003;24(6):465-70.

Farina D, Merletti R. Comparison of algorithms for estimation of EMG variables during voluntary isometric contractions. J Electromyogr Kinesiol 2000;10(5):337-49.

Hirashima M, Kadota H, Sakurai S, Kudo K, Ohtsuki TJ. Sequential muscle activity and its functional role in the upper extremity and trunk during overarm throwing. Sports Sci 2002;20(4):301-10.

Hodges PW, Bui BH. A comparison of computer-based methods for the determination of onset of muscle contraction using electromyography. Electroencephalogr Clin Neurophysiol 1996;101(6):511-9.

Hodges PW. Changes in motor planning of feedforward postural responses of the trunk muscles in low back pain. Exp Brain Res 2001;141(2):261-6.

Horton JF, Lindsay DM, Macintosh BR. Abdominal muscle activation of elite male golfers with chronic low back pain. Med Sci Sports Exerc 2001;33(10):1647-54.

Hug F. Can muscle coordination be precisely studied by surface electromyography? J Electromyogr Kinesiol 2011:21(1):1-12.

Hume PA, Keogh J, Reid D. The role of biomechanics in maximising distance and accuracy of golf shots. Sports Med 2005;35(5):429-49.

Jöllenbeck J. Methodological limitations of EMG-based bio-mechanical motion analysis. ISBS - conference proceedings archive, 18 International symposium on biomechanics in sports; 2000.

Konrad P. The ABC of EMG: a practical introduction to kinesiological electromyography. USA: Noraxon Inc. 2005.

Leader 3rd JK, Boston JR, Moore CA. A data dependent computer algorithm for the detection of muscle activity onset and offset from EMG recordings. Electroencephalogr Clin Neurophysiol 1998;109(2):119-23.

Lee J, Jung MY, Kim SH. Reliability of spike and turn variables of surface EMG during isometric voluntary contractions of the biceps brachii muscle. J Electromyogr Kinesiol 2011;21(1):119-27.

McGill SM. Electromyographic activity of the abdominal and low back musculature during the generation of isometric and dynamic axial trunk torque: implications for lumbar mechanics. J Orthop Res. 1991;9(1):91-103.

McGill SM, Chaimberg JD, Frost DM, Fenwick CM. Evidence of a double peak in muscle activation to enhance strike speed and force: an example with elite mixed martial arts fighters. J Strength Cond Res 2010;24(2):348-57.

Micera S, Sabatini AM, Dario P. An algorithm for detecting the onset of muscle contraction by EMG signal processing. Med Eng Phys 1998;20(3):211-5.

Morey-Klapsing G, Arampatzis A, Brüggemann GP. Choosing EMG parameters: comparison of different onset determination algorithms and EMG integrals in a joint stability study. Clin Biomech (Bristol, Avon) 2004;19(2):196-201.

Pink M, Perry J, Jobe F. EMG analysis of the trunk in golfers. Am J Sports Med 1993;21(3):385-8

Solnik S, DeVita P, Rider P, Long B, Hortobágyi T. Teager-Kaiser Operator improves the accuracy of EMG onset detection independent of signal-to-noise ratio. Acta Bioeng Biomech 2008;10(2):65-8.

Solnik S, Rider P, Steinweg K, DeVita P, Hortobágyi T. Teager-Kaiser energy operator signal conditioning improves EMG onset detection. Eur J Appl Physiol 2010;110(3):489-98.

Soylu AR, Arpinar-Avsar P. Detection of surface electromyography recording time interval without muscle fatigue effect for biceps brachii muscle during maximum voluntary contraction. J Electromyogr Kinesiol 2010;20(4): $773-6$.

Staude G, Flachenecker C, Wolf W. Onset detection in surface electromyographic signals: a systematic comparison of methods. EURASIP J Appl Signal Process 2001;2001(2):67-81.

Vaisman L, Zariffa J, Popovic MR. Application of singular spectrum-based change- point analysis to EMG-onset detection. J Electromyogr Kinesiol 2010:20(4):750-60.

Van Boxtel GJ, Geraats LH, Van den Berg-Lenssen MM, Brunia CH. Detection of EMG onset in ERP research. Psychophysiology 1993;30(4):405-12.

Watkins R, Uppal G, Perry J, Pink M, Dinsay J. Dynamic electromyographic analysis of trunk musculature in professional golfers. Am J Sports Med 1996;24(4):535-8.

Wong YM, Ng GY. The double peak-to-peak analysis for determining EMG onset of muscle contraction. Electromyogr Clin Neurophysiol 2005;45(5):267-71.

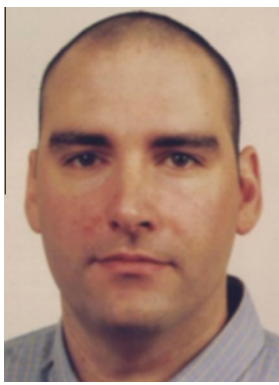

Luís Silva is graduated in Sport Science - Physical Condition by the Sport Sciences School of Rio Maior, Management by the University Lusíada, and received the M. Sc. at the Faculdade de Motricidade Humana da Universidade Técnica de Lisboa - Portugal. He's currently $\mathrm{Ph}$. D. student and researcher in the Laboratory of Motor Behavior of the Faculdade de Motricidade Humana da Universidade Técnica de Lisboa (CIPER Interdisciplinary Center for the Study of Human Performance), and professor of Anatomophysiology in University Lusíada. His research topics are electromyography, kinesiology and statistics.

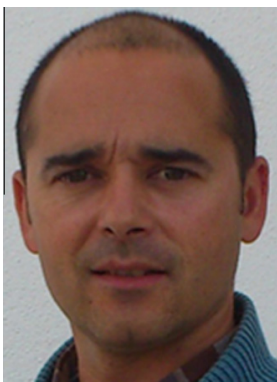

Sérgio Marta, born in 1974, graduated in Sport Science, received the $\mathrm{M}$. Sc. degree in Young Athlete Training in 2007 from the Faculdade de Motricidade Humana da Universidade Técnica de Lisboa. Former professor of Anatomophisiology in the Portuguese Piaget Institute Almada Campus (2000 - 2008), is currently a Human Kinetics Ph.D. student and an investigator of the research unit of the Faculdade de Motricidade Humana da Universidade Técnica de Lisboa, the Interdisciplinary Center for the Study of Human Performance (CIPER). His main interests are motion analysis, electromyography and kinesiology in sports.

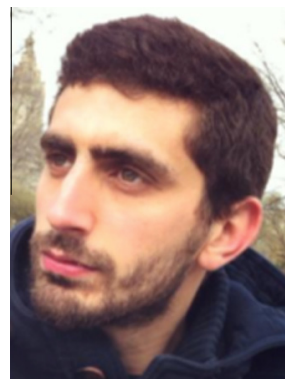

João Rocha Vaz is graduated in Psychomotricity (2009) and in Physical Therapy (2013). Currently he is a PhD Student in Motor Behavior at the Faculdade de Motricidade Humana da Universidade Técnica de Lisboa. He has also been working as a research assistant at Laboratory of Motor Behaviour, since 2009. Research Topics: electromyography, muscle coordination, neuromuscular function, kinesiology.

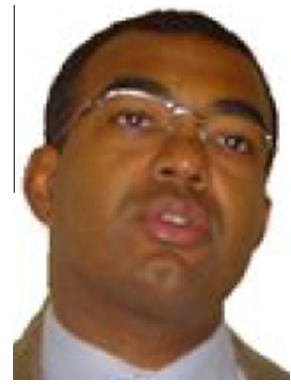

Orlando J. Fernandes, born in 1962 is graduated, Master and $\mathrm{PhD}$, in Sports Science. Currently is assistant Professor in Évora University, teaching Analyses of Human Movement and Biomechanics in Sports science and Physical therapy. His research focus on Biomechanical Analysis of human movement specifically related to injury prevention and nonlinear methods applied to human movement. Research topics: Sports and physical therapy Biomechanics, Motor Control, Neuromuscular function, Movement Variability and Data processing. 


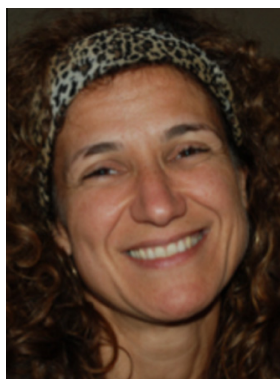

Maria António Castro graduated in Physiotherapy in 1987 at Coimbra's College of Health (ESTESC). PhD in Physiotherapy-Human Kinetics at the Faculdade de Motricidade Humana da Universidade Técnica de Lisboa - Portugal (2008). Currently, she is Adjunct Professor of ESTES Coimbra where she teaches Human Movement, Manual Therapy and Exam and evaluation. She is a researcher of University of Coimbra's Mechanical Engineering Research Center. Physiotherapist of Women's Basketball Senior National Team (1995 to 2005). Founder and president (1998 to 2005) of the Portuguese Physiotherapists' Trade Union. Research interest: movement analysis, sports injuries and injury prevention.

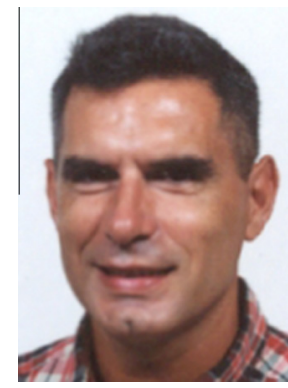

Pedro Pezarat-Correia, born in 1958, is graduated in Physical Education, PhD in Human Kinetics (Faculdade de Motricidade Humana da Universidade Técnica de Lisboa - Portugal) in 1995. Currently is Associated Professor of the Universidade Técnica de Lisboa where teaches disciplines of Anatomophysiology, Kinesiology and Neuromuscular Function in graduate and postgraduate courses. He is researcher of the Laboratory of Motor Behavior and member of the Interdisciplinary Centre for the Study of Human Performance (CIPER), the Research Unit of the Faculdade de Motricidade Humana da Universidade Técnica de Lisboa. Research topics: electromyography, kinesiology, neuromuscular function. 